\title{
IGF-1 is an independent predictor of retinal arterioles remodeling in subjects with uncontrolled acromegaly
}

\author{
Antonio Gallo, 2,*, Emmanuelle Chaigneau ${ }^{1, *}$, Christel Jublanc ${ }^{1}$, David Rosenbaum ${ }^{1}$, Alessandro Mattina ${ }^{1, t}$, \\ Michel Paques ${ }^{3}$, Florence Rossant ${ }^{4}$, Xavier Girerd' ${ }^{1}$, Monique Leban ${ }^{5}$ and Eric Bruckert ${ }^{1}$
}

${ }^{1}$ Department of Endocrinology, Metabolism and Cardiovascular Prevention, University Hospital Pitié-Salpêtrière, APHP, Sorbonne University Paris, Paris, France, ${ }^{2}$ Sorbonne Universités, UPMC Université Paris 06, INSERM 1146, CNRS 7371, Laboratoire d'imagerie Biomédicale, Paris, France, ${ }^{3}$ Département d'Ophtalmologie, Hôpital des Quinze-Vingts, Centre d'Investigation Clinique INSERM-DHOS 1423, Institut de la Vision, Sorbonne Universités, CNRS, Paris, France, ${ }^{4}$ Institut Supérieur d'Eléctronique de Paris, Paris, France, and ${ }^{5}$ Laboratory of Endocrine Biochemistry, University Hospital Pitié-Salpêtrière, APHP, Paris, France

*(A Gallo and E Chaigneau contributed equally to this work)

${ }^{\dagger}$ (A Mattina is now at Diabetes and Islet Transplantation Unit, Department of Diagnostic and Therapeutic Services, IRCCS-ISMETT (Istituto Mediterraneo per i Trapianti e Terapie ad alta specializzazione), UPMC, Palermo, Italy)

Correspondence should be addressed to A Gallo

Email

antonio.gallo@aphp.fr

\begin{abstract}
Context: Cardiovascular disease is one of the main causes of morbidity in active acromegaly due to the increased prevalence of risk factors and arterial consequences of increased growth hormone levels. No in vivo study has evaluated the consequences of acromegaly on the retinal microvasculature.

Objective: The aim of this study was to identify in vivo the presence of morphological alterations of retinal arterioles in subjects with acromegaly.

Patients and methods: Single-center retrospective study of a cohort of 60 subjects with acromegaly, matched to 60 controls, who were referred for adaptive optics camera (AOC) from September 2014 to December 2016. Of the subjects with acromegaly, 19 had an active disease (AD) and 41 a controlled disease (CD) based on the IGF1 ratio (IGF1r). Retinal arteriolar remodeling was previously assessed using adaptive optics camera (AOC) in order to measure wall-to-lumen ratio (WLR), wall thickness (WT), internal diameter (ID) and wall cross sectional area (WCSA).

Results: WLR was significantly higher in AD subjects compared to CD subjects and controls (AD: $0.311 \pm 0.06, C D$ : $0.279 \pm 0.04$, controls: $0.281 \pm 0.04, P=0.031$ ). A significant positive correlation was observed between WLR and IGF-1r $\left(R^{2}=0.215, P<0.001\right)$, even after adjustment for gender, age, systolic blood pressure (SBP) and the presence of dopamine agonist treatment $\left(R^{2}=0.406, P<0.001\right)$. Retinal arteriolar anatomical indices were comparable between $C D$ and controls. Conclusion: Active acromegaly is associated with the presence of small retinal arteriolar remodeling. These results provide new perspectives to better stratify cardiovascular risk and consequently optimize treatment in acromegaly.
\end{abstract}

\section{Introduction}

Acromegaly is a rare chronic disease caused by growth hormone (GH) hypersecretion. It is characterized by overgrowth of tissues, which leads to a considerable burden of complications such as cardio- and cerebrovascular morbidities $(1,2,3)$. Acromegaly is associated (c) 2020 European Society of Endocrinology Printed in Great Britain with an increased prevalence of cardiovascular risk factors such as arterial hypertension, diabetes mellitus, dyslipidaemia, sleep apnea and biventricular concentric hypertrophy. These risk factors account for the increased cardiovascular and cerebrovascular morbidity and

Published by Bioscientifica Ltd. 
mortality $(1,4,5,6,7)$. However, in addition to these risk factors, abnormal secretion of $\mathrm{GH}$ and insulin-like growth factor 1 (IGF1) may have a direct role in the atherosclerotic changes involving large conduit arteries $(8$, $9,10,11,12,13,14)$. There are no in vivo data on possible structural changes (remodeling) of small arteries and arterioles in patients suffering from acromegaly that have been realised noninvasively. Among all microcirculatory districts, the retina represents an exceptional window to microcirculation, and novel advances in retinal digital imaging make the study of in vivo morphological and functional microvascular impairment easier and more precise. Several studies have demonstrated a relationship between functional and morphological changes in retinal microvasculature and cardio/cerebrovascular risk $(15,16,17,18,19,20)$. Previous studies have reported structural changes in small arteries in acromegaly (21, 22), but as recently highlighted, the pathophysiological mechanisms behind the interaction between GH/IGF1 and microcirculation are still unclear (23).

The aim of our study was to identify the presence of subclinical morphological alterations of retinal arterioles in subjects with acromegaly using the adaptative optics camera (AOC), a novel camera with a near histological resolution. We also analyzed whether these remodeling processes might be linked to the control of the disease evaluated by IGF1 levels.

\section{Subjects and methods}

\section{Study population}

We conducted a single retrospective study including all patients $(n=60)$ with a diagnosis of acromegaly for whom an AOC analysis was performed between September 2014 and December 2016. Inclusion criteria were diagnosis of acromegaly for at least 6 months compared to the date of AOC according to published guidelines (24) and the presence of pituitary adenoma on brain imaging (4).

Exclusion criteria were ophthalmological disease interfering with adaptative optics analysis (i.e. cataract) or optic nerve compression and/or intra-cranial hypertension.

Subjects with acromegaly were stratified according to disease activity using IGF1 ratio (IGF1r). The IGF1r was defined as the ratio between subject's IGF1 levels and the upper limits of IGF1 reference range. The reference values were taken from a validation study of six different immunoassays on a large random sample of 911 French adults and were age, sex and immunoassay-specific (25).
Active disease (AD) was defined as an IGF1r $>1$ or IGF1 $r \leq 1$ for less than 6 months from AOC examination. Patients were defined as having controlled disease (CD) if IGF1r was $\leq 1$ for $\geq 6$ months $(8,26)$ from AOC examination. GH was not used to define the control of the disease since some subjects were receiving a $\mathrm{GH}$ receptor antagonist.

\section{Matching procedure for the control population}

Non-acromegalic control subjects $(n=60)$ for whom the result of an AOC was available were matched for age, gender, systolic blood pressure (SBP), diastolic blood pressure (DBP), presence of diabetes mellitus and/or antihypertensive treatment.

The study was not approved by a medical ethical or institutional review board, as it is not deemed necessary by the French law for observational non-interventional studies on humans. However, formal approval from participants was obtained for using patients data for study purposes, and data handling was performed according to national laws. The study was registered at the Greater Paris University Hospitals (GPUH) Clinical Data Warehouse (CDW), registration number 20190712115017.

\section{Retinal arterioles examination by adaptive optics}

Ocular fundus images were obtained using a commercially available flood-illumination AOC retinal camera ( $\mathrm{rtx} 1^{\mathrm{TM}}$; Imagine Eyes, Orsay, France). We used this camera to measure wall thickness (WT), internal diameter (ID) and to calculate wall-to-lumen ratio (WLR) and wall cross sectional area (WCSA) on retinal arteriolar microvasculature. The detailed procedure of images acquisition and treatment has been previously reported (Fig. 1) (27).

The reference site was a segment of the superotemporal artery of the right eye, at least $250 \mu \mathrm{m}$ long with an inner diameter of at least $50 \mu \mathrm{m}$, devoid of bifurcations. The supero-temporal right arteriole was selected in an area of 0.5 to 1 disc diameter from the optic disc (28).

A trained technician $(\mathrm{KC})$ blind to patient's data performed all the image analysis. Intra-observer reproducibility of microvasculature anatomical indices was already published $(28,29)$.

\section{Hormonal measurement}

IGF1 plasma levels were measured using an automated chemiluminescence immunoassay LIAISON XL. GH plasma was measured using an automated immunoassay LIAISON hGH. 

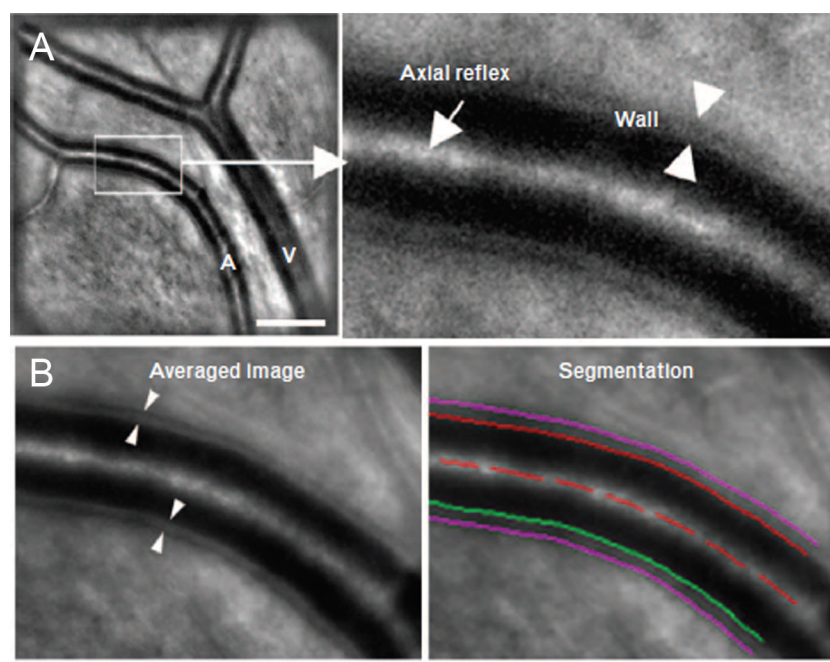

C

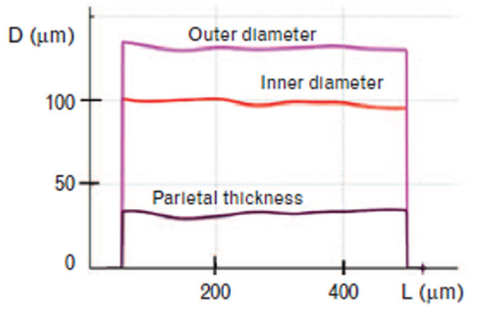

\section{Figure 1}

Adaptive optics (AO) segmentation of the right supero-

temporal retinal arteriole. (A) Representation of a single frame with a segment of the arteriole (A) and venule (V). On the right, magnification of the white square: the arrowheads delimit the arteriolar wall (bar, $250 \mu \mathrm{m}$ ). (B) Arteriolar segment analysed and averaged. (C) Morphogram of the segmented vessel ( $D$, diameter; L, length). Reproduced with permission from Koch et al. (27). A full color version of this figure is available at https://doi.org/10.1530/EJE-19-0390.

\section{Cardiovascular risk factors assessment}

Office brachial blood pressure (BP) was measured in standard conditions with the patient seated for at least 5 min during the outpatient visit using an oscillometric device (OMRON 905) simultaneously to AOC assessment. Office arterial hypertension was defined as $\mathrm{SBP} \geq 140$ $\mathrm{mmHg}$ and/or DBP $\geq 90 \mathrm{mmHg}$ or if the subject was on antihypertensive medication.

Levels of glucose, $\mathrm{HbA}_{\mathrm{C}}$, total cholesterol, triglycerides, LDL and HDL cholesterol of 120 subjects were analyzed.

Dyslipidemia was defined as a total serum cholesterol level of $>5.0 \mathrm{mmol} / \mathrm{L}$, serum low-density lipoprotein (LDL) cholesterol level of $>3.0 \mathrm{mmol} / \mathrm{L}$, serum high-density lipoprotein (HDL) cholesterol level of
$<1.0 \mathrm{mmol} / \mathrm{L}$ for men and $<1.2 \mathrm{mmol} / \mathrm{L}$ for women, or serum triglycerides level of $>1.7 \mathrm{mmol} / \mathrm{L}$ or a daily intake of any lipid-lowering medication.

Diabetes was defined as two fasting blood glucose values $>7 \mathrm{mmol} / \mathrm{L}$, or one blood glucose value $>11.11$ $\mathrm{mmol} / \mathrm{L}$ at any time of the day or a daily intake of antidiabetes therapy.

Smoking habits were divided into either current smoking (defined as any cigarette in the last month) or no smoking.

\section{Statistical analysis}

Socio-demographic and clinical characteristics, biological parameters and imaging data are reported. Parametric continuous variables are expressed as mean \pm s.D. Nonparametric continuous variables are presented as median (inter-quartile range). Qualitative variables are reported as frequency.

Primary analysis used ANOVA to compare all reported data for parametric variables, whereas Kruskall-Wallis test was used for comparison among non-parametric variables between the $\mathrm{AD}$ subjects, $\mathrm{CD}$ subjects and controls.

Within the acromegaly groups (active and controlled disease), predictors of retinal microvasculature parameters were analyzed using univariate and multivariate analyses adjusting for potential confounding factors, such as age, gender, systolic blood pressure, IGF1r and dopamine agonist treatment. Non-parametric variables were log- transformed.

All included subjects were analyzed. Statistical analyzes were performed using SPSS software version 23 (SPSS). Statistical tests were bilateral, and the $P$ threshold used was $<0.05$.

\section{Results}

\section{Demographic and treatment of acromegaly}

Sixty subjects with acromegaly and 60 matched control subjects were included. Among subjects with acromegaly, 19 with $\mathrm{AD}$ and 41 with $\mathrm{CD}$. Subjects characteristics are reported in Table 1.

Higher IGF1, IGF1r and GH levels were found in AD subjects compared to $\mathrm{CD}$ subjects. The two acromegaly groups had a similar disease duration.

No differences in the prevalence of arterial hypertension, diabetes, dyslipidaemia or in smoking 
Table 1 Main characteristics of study population stratified according to disease activity and controls.

\begin{tabular}{l}
\hline \\
\hline Demographics \\
Age - years \\
Gender - Male/Female \\
BMI - kg/m² \\
Median Follow-up - years \\
Somatotropic axis \\
IGF1 - $\mu$ g/L \\
IGF1 ratio \\
GH - $\mu$ g/L \\
Office blood pressure \\
Antihypertensive Treatment - $n(\%)$ \\
SBP - mmHg \\
DBP - mmHg \\
Other cardiovascular risk factors \\
Diabetes - $n(\%)$ \\
Dyslipidemia - $n(\%)$ \\
Smoke - $n(\%)$ \\
Cardiovascular event $-n(\%)$ \\
Cerebrovascular event - $n(\%)$
\end{tabular}

\begin{tabular}{c} 
Controls $(n=60)$ \\
\hline $51.1 \pm 12.1$ \\
$32 / 28$ \\
$27.9 \pm 6.7$ \\
\\
$/$ \\
$/$
\end{tabular}

20 (32.8)

$124.1 \pm 18.9$

$71.7 \pm 11.3$

$$
\begin{gathered}
9(14.8) \\
18(29.5) \\
9(14.8)
\end{gathered}
$$

-

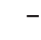

\begin{tabular}{c}
\hline Controlled disease $(n=41)$ \\
\hline $49.9 \pm 13.5$ \\
$25 / 16$ \\
$29.2 \pm 5.6$ \\
$12 \pm 7.4$
\end{tabular}

$170.0(122.5-208.7)$

$0.62(0.52-0.76)$

$0.22(0.16-0.71)$

$11(26.8)$

$122.2 \pm 12.6$

$71.6 \pm 10.8$

6 (14.6)

$13(31.7)$

$7(17.1)$

0

$1(1.7)$

\begin{tabular}{c}
\hline Active disease $(n=19)$ \\
\hline $55.4 \pm 10.6$ \\
$7 / 12$ \\
$31.5 \pm 9.1$ \\
$10 \pm 7.0$ \\
$329.0(270-383)$ \\
$1.22(1-1.5)$ \\
$1.37(0.38-2.31)$ \\
$8(42.1)$ \\
$126.4 \pm 21.7$ \\
$74.7 \pm 13.4$ \\
$3(15.8)$ \\
$7(36.8)$ \\
$2(10.5)$ \\
0 \\
0
\end{tabular}

\begin{tabular}{c}
\hline P between groups \\
\hline ns \\
ns \\
ns \\
ns \\
$<0.001$ \\
$<0.001$ \\
0.03 \\
ns \\
ns \\
ns \\
ns \\
ns \\
$n s$ \\
$n s$ \\
$n s$
\end{tabular}

DBP, diastolic blood pressure; IGF1 SDS, insulin-like growth factor-1 standard deviation score; SBP, systolic blood pressure.

status were observed among the three groups. AD subjects showed lower total cholesterol and LDL cholesterol levels compared to controls (Supplementary Additional Table 1, see section on supplementary materials given at the end of this article).

The most common therapeutic strategy was the combination of surgery and pharmacological treatment (AD: $68.4 \%$ vs $\mathrm{CD}: 75.6 \% P=$ ns). Subjects with $\mathrm{AD}$ received more dopamine agonists than $\mathrm{CD}$ subjects. Somatostatin analogues and $\mathrm{GH}$ receptors antagonists were equally used in AD and CD groups (Supplementary Additional Table 2).

\section{Retinal small arterioles anatomical indices}

A significant WLR increase was found in AD subjects compared to CD subjects and controls, while WLR did not differ between CD and controls (AD: $0.311 \pm 0.056$, CD: $0.279 \pm 0.044$, controls: $0.281 \pm 0.043 ; P=0.031$ across groups). Two comparative AOC images of WLR in AD and control are provided in Fig. 2.

Also, a significant arteriolar ID reduction was observed in $\mathrm{AD}$ subjects compared to $\mathrm{CD}$ subjects, whereas $\mathrm{CD}$ and control subjects exhibited the same ID (AD: 74.1 \pm 11.25 , CD: $80.11 \pm 9.4$, controls: $76.14 \pm 8.9 ; \quad P=0.04$ across groups) (Fig. 3).

Finally, while WCSA was not different among the three groups, and a non-significant trend toward wall thickening in $\mathrm{AD}$ subjects was observed compared to $\mathrm{CD}$ and controls $(P=0.125)$.

\section{Univariate analysis of retinal arterioles anatomical indices determinants}

IGF1r was positively correlated to WLR $\left(R^{2}=0.215\right.$, $P<0.001)$ and negatively to internal diameter $\left(R^{2}=0.124\right.$, $P=0.006$ ) (Fig. 4). No significant correlation was observed between IGF1r and WT or WCSA (Supplementary Additional Table 3).
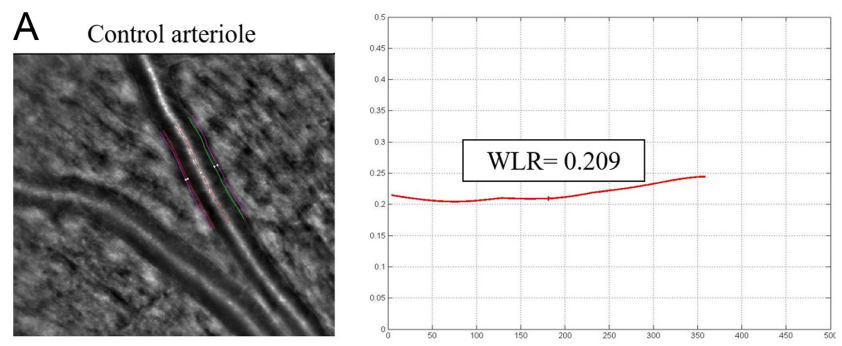

B Acromegaly arteriole
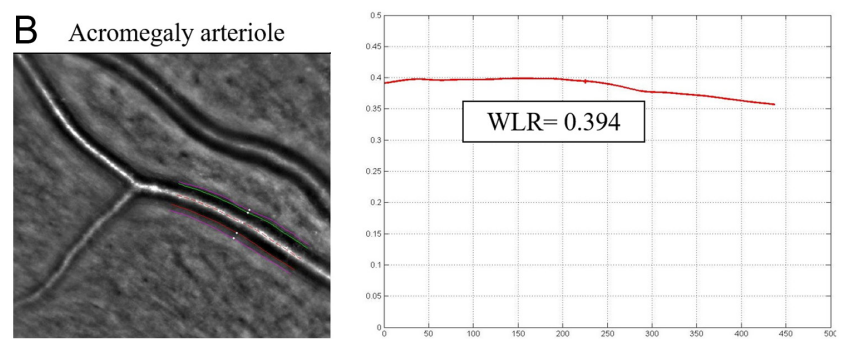

Figure 2

Retinal microvessels and arteriolar WLR measurement in control subjects compared to acromegalic subjects. A full color version of this figure is available at https://doi.org/10.1530/ EJE-19-0390. 

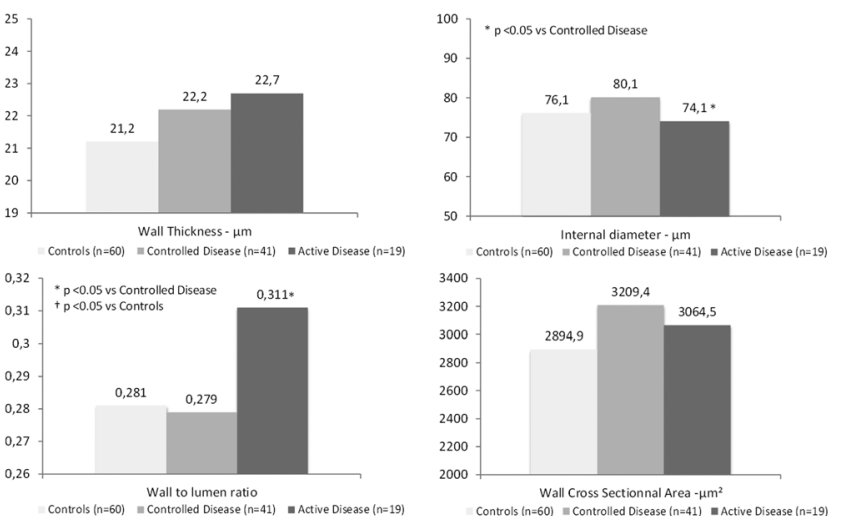

acromegaly

\section{Discussion}

Over the last decades, the improved management of acromegaly and cardiovascular risk factors has led to a significant decrease in the incidence of cardiovascular disease (30). The duration of exposure to abnormal GH/IGF1 levels and the subsequent normalization of GH and IGF1 plasma levels seem to have a role in this phenomenon $(14,31)$. However, the role of GH/IGF1 on vascular function and atherosclerosis $(32,33,34)$ remains to be fully explored. Similarly, beyond the treatment of classical risk factors, the effect of treatment aiming at normalizing IGF1 and GH levels is not known. Indeed, different therapeutic strategies have shown different outcomes on the reduction of cardiovascular and metabolic risk factors (35).

The study of the microcirculation in acromegaly has been hampered by the limited explorability of microvascular territories. The WLR, as a marker of microvascular remodeling, has been confirmed as an independent prognostic marker of cardiovascular events $(15,16)$. Recent advances in retinal digital imaging have made the study of morphological and functional microvascular impairment easier and more precise. The retina represents an exceptional window to a noninvasive in vivo exploration of microcirculation. Retinal vessels share structural and physiological features with cerebral microcirculation (14), and several studies have found a relationship between retinal microvascular impairment and increased risk of stroke or cognitive decline $(19,36)$.

A relationship with cardiovascular dysfunction has also been shown (37) suggesting that an early onset of retinal abnormalities might precede arterial hypertension, heart failure and could be linked with an increased cardiovascular morbidity and mortality (38).

In acromegaly, previous studies have already shown a vascular remodeling of small arteries $(21,22)$. While in these studies, a hypertrophic remodeling pattern was observed, characterized by an increased WLR, WT and WCSA, we observed a eutrophic remodeling in retinal arterioles of $\mathrm{AD}$ subjects compared to $\mathrm{CD}$ subjects and controls, characterized by an increased WLR mainly due to a significant reduction in ID, a non-significant trend toward an increased WT and no changes in WCSA.

Three possible explanations for the discrepancy between eutrophic vs hypertrophic remodeling exist. The first is related to the vascular territory explored. It has been demonstrated that subjects with acromegaly have a blunted dilatory response despite a normal vascular smooth cell ability to produce vasodilating hormones.

Correlation between IGF1-ratio and retinal arteriolar WLR (panel A) and caliber (panel B). 
Sympathetic-mediated vasoconstrictive response might be increased in acromegaly $(3,21,39)$. As the retina is devoid of adrenergic innervation (18), retinal arteriolar remodeling would therefore represent a reflection of an indirect action of the sympathetic overdrive in acromegaly. Secondly, the technique used for the retinal microvascular imaging differs from previous techniques used for gluteal small arteries. Although this may account for the different results observed, the pressure myography has been found highly correlated with AOC (40). What is still different is that AOC captures in vivo images of retinal microvasculature, whereas pressure myography assesses arterial anatomy and physiology in standardized conditions that are exempt from physiological local stimuli. The absence of hypertrophy in our cohort suggests that the acromegaly-induced remodeling may be a reversible process in treatment-stabilized patients as highlighted in a previous study on coronary microcirculation (31). This is supported by the finding that the increase in WLR was a consequence of ID decrease, which is more likely to reflect myogenic tonus activation. Interestingly, this correlation was independent of SBP, which is one of the determinants of WLR. In our study, a reduction in the retinal arteriolar caliber has been associated with an increased risk of hypertension and cardiovascular morbidity and mortality $(17,20)$. In a previous study on AOC, hypertensive patients exhibited an increased WLR associated with a reduced ID, and after SBP reduction a normalization of the WLR was observed, due to vasodilation without changes in WT (18). This suggests that the reversal of the vasoconstriction in acromegaly patients with $\mathrm{AD}$ could be related to the same phenomenon, where GH/ IGF1 reduction would normalize microvascular anatomy and function. This hypothesis is supported by previous findings, where no differences in vascular involvement between $\mathrm{CD}$ acromegaly patients and controls was observed $(9,26)$. An exploration of venules is currently possible with AOC. In a previous study, we showed that venules and arterioles could interact even without a direct contact, determining venous nicking without contact (41). Whether GH or IGF1 has a role on venular morphology has not been explored and will be the focus of further research, as previous studies have shown that inflammation as well as vasoactive substances may play a role on the arterio-venous interaction $(42,43)$.

Our cohort of acromegalic patients shares similar features with those observed in other cohorts $(14,30)$. We found a similar prevalence of hypertension, coronary heart disease and/ or cerebrovascular events to that observed in The French Acromegaly registry (30), which provides 
information about the incidence of comorbidities during the follow-up and is thus comparable to our cohort. Only diabetes mellitus was slightly more prevalent in the French Acromegaly registry ( $25 \%$ vs $15 \%$ in our study). Interestingly, patients with active disease had lower lipid levels compared to controlled disease and controls: the concomitant higher GH levels may account for this difference, irrespective of the therapeutic strategy, as it enhances the expression of LDL-receptor on the hepatic cell surface (44).

There are several limitations to our study. The first one could be a possible selection bias due to the retrospective nature of the study. Also, we could not provide IGF1 values in the control group: even if they were not known to have acromegaly, we could not compare microvasculature remodeling according to IGF1r. Finally, it could have been useful to have a measure of microcirculation endothelial function, but this analysis, although coupled to AOC, has not yet been standardizedis not yet available on AOC.

In conclusion, we identified the presence of small retinal arterioles remodeling in a large population of acromegalic subjects with active disease using the noninvasive adaptive optics camera. This remodeling was characterized by a vasoconstriction that was independently correlated with IGF1r. Importantly, subjects with a chronically controlled disease showed a similar microvascular pattern compared to matched controls.

To our knowledge, our study is the first one which evaluated the retinal microvasculature using a noninvasive in vivo procedure in subjects with acromegaly and where a biomarker was shown to be associated with microvascular remodeling indexes as evaluated by AOC. Our results complement in vitro studies on small arteries in acromegaly. The use of a noninvasive exploration of the retinal microcirculation could provide a new tool for cardiovascular risk assessment and treatment follow-up in acromegaly patients. It also might help understand early changes in the microvasculature of these patients.

\section{Supplementary materials}

This is linked to the online version of the paper at https://doi.org/10.1530/ EJE-19-0390

\section{Declaration of interest}

The authors declare that there is no conflict of interest that could be perceived as prejudicing the impartiality of this study.

\section{Funding}

This research did not receive any specific grant from any funding agency in the public, commercial or not-for-profit sector.

\section{Acknowledgments}

The authors thank Kanagasabapathy Caroline for the adaptive optics images acquisition and analysis.

\section{References}

1 Melmed S, Casanueva FF, Klibanski A, Bronstein MD, Chanson P, Lamberts SW, Strasburger CJ, Wass JAH \& Giustina A. A consensus on the diagnosis and treatment of acromegaly complications. Pituitary 201316 294-302. (https://doi.org/10.1007/s11102-012-0420-x)

2 Chanson P, Salenave S \& Kamenicky P. Chapter 14 - Acromegaly. In Handbook of Clinical Neurology [Internet] [cited 2019 May 12], pp 197-219. (Clinical Neuroendocrinology; vol. 124). Eds E Fliers, M Korbonits \& JA Romijn. Elsevier, 2014. (available at: http://www.scie ncedirect.com/science/article/pii/B9780444596024000149)

3 Colao A, Ferone D, Marzullo P \& Lombardi G. Systemic complications of acromegaly: epidemiology, pathogenesis, and management. Endocrine Reviews 200425 102-152. (https://doi. org/10.1210/er.2002-0022)

4 Katznelson L, Laws ER, Melmed S, Molitch ME, Murad MH, Utz A, Wass JAH \& Endocrine Society. Acromegaly: an Endocrine Society clinical practice guideline. Journal of Clinical Endocrinology and Metabolism 201499 3933-3951. (https://doi.org/10.1210/jc.20142700)

5 Dal J, Feldt-Rasmussen U, Andersen M, Kristensen LØ, Laurberg P, Pedersen L, Dekkers OM, Sørensen HT \& Jørgensen JOL. Acromegaly incidence, prevalence, complications and long-term prognosis: a nationwide cohort study. European Journal of Endocrinology 2016175 181-190. (https://doi.org/10.1530/EJE-16-0117)

6 Mercado M, Gonzalez B, Vargas G, Ramirez C, de los Monteros ALE, Sosa E, Jervis P, Roldan P, Mendoza V, Lopez-Félix B et al. Successful mortality reduction and control of comorbidities in patients With acromegaly followed at a highly specialized multidisciplinary clinic. Journal of Clinical Endocrinology and Metabolism 201499 4438-4446. (https://doi.org/10.1210/jc.2014-2670)

7 Arosio M, Reimondo G, Malchiodi E, Berchialla P, Borraccino A, De Marinis L, Pivonello R, Grottoli S, Losa M, Cannavò S et al. Predictors of morbidity and mortality in acromegaly: an Italian survey. European Journal of Endocrinology 2012167 189-198. (https://doi.org/10.1530/ EJE-12-0084)

8 Yaron M, Izkhakov E, Sack J, Azzam I, Osher E, Tordjman K, Stern N \& Greenman Y. Arterial properties in acromegaly: relation to disease activity and associated cardiovascular risk factors. Pituitary 201619 322-331. (https://doi.org/10.1007/s11102-016-0710-9)

9 Kartal I, Oflaz H, Pamukçu B, Meriç M, Aral F, Ozbey N \& Alagöl F. Investigation of early atherosclerotic changes in acromegalic patients. International Journal of Clinical Practice 201064 39-44. (https://doi.org/10.1111/j.1742-1241.2008.01750.x)

10 Colao A, Spiezia S, Cerbone G, Pivonello R, Marzullo P, Ferone D, Di Somma C, Assanti AP \& Lombardi G. Increased arterial intima-media thickness by B-M mode echodoppler ultrasonography in acromegaly. Clinical Endocrinology 200154 515-524. (https://doi.org/10.1046/ j.1365-2265.2001.01256.x)

11 Colao A, Spinelli L, Cuocolo A, Spiezia S, Pivonello R, di Somma C, Bonaduce D, Salvatore M \& Lobardi G. Cardiovascular consequences of early-onset growth hormone excess. Journal of Clinical Endocrinology and Metabolism 200287 3097-3104. (https://doi. org/10.1210/jcem.87.7.8573)

12 Brevetti G, Marzullo P, Silvestro A, Pivonello R, Oliva G, di Somma C, Lombardi G \& Colao A. Early vascular alterations in acromegaly. Journal of Clinical Endocrinology and Metabolism 200287 3174-3179. (https://doi.org/10.1210/jcem.87.7.8643)

13 Paisley AN, Banerjee M, Rezai M, Schofield RE, Balakrishnannair S, Herbert A, Lawrance JAL, Trainer PJ \& Cruickshank JK. Changes in arterial stiffness but not carotid intimal thickness in acromegaly. 
Journal of Clinical Endocrinology and Metabolism 201196 1486-1492. (https://doi.org/10.1210/jc.2010-2225)

14 Petrossians P, Daly AF, Natchev E, Maione L, Blijdorp K, SahnounFathallah M, Auriemma R, Diallo AM, Hulting AL, Ferone D et al. Acromegaly at diagnosis in 3173 patients from the Liège Acromegaly Survey (LAS) Database. Endocrine-Related Cancer 201724 505-518. (https://doi.org/10.1530/ERC-17-0253)

15 Rizzoni D, Porteri E, Boari GEM, De Ciuceis C, Sleiman I, Muiesan ML, Castellano M, Miclini M \& Agabito-Rosei E. Prognostic significance of small-artery structure in hypertension. Circulation 2003108 2230-2235. (https://doi.org/10.1161/01. CIR.0000095031.51492.C5)

16 Mathiassen ON, Buus NH, Sihm I, Thybo NK, Mørn B, Schroeder AP, Thygesen K, Aalkjaer C, Lederballe O, Mulvany MJ et al. Small artery structure is an independent predictor of cardiovascular events in essential hypertension. Journal of Hypertension 200725 1021-1026. (https://doi.org/10.1097/HJH.0b013e32805bf8ed)

17 McGeechan K, Liew G, Macaskill P, Irwig L, Klein R, Klein BEK, Wang JJ, Mitchell P, Vingerling JR, Dejong PTVM et al. Meta-analysis: retinal vessel caliber and risk for coronary heart disease. Annals of Internal Medicine 2009151 404-413. (https://doi.org/10.7326/00034819-151-6-200909150-00005)

18 Rosenbaum D, Mattina A, Koch E, Rossant F, Gallo A, Kachenoura N, Paques M, Redheuil A \& Girerd X. Effects of age, blood pressure and antihypertensive treatments on retinal arterioles remodeling assessed by adaptive optics. Journal of Hypertension 201634 1115-1122. (https://doi.org/10.1097/HJH.0000000000000894)

19 Wong TY, Klein R, Couper DJ, Cooper LS, Shahar E, Hubbard LD, Wofford MR \& Sharrett AR. Retinal microvascular abnormalities and incident stroke: the Atherosclerosis Risk in Communities Study. Lancet 2001358 1134-1140. (https://doi.org/10.1016/S01406736(01)06253-5)

20 Wang JJ, Rochtchina E, Liew G, Tan AG, Wong TY, Leeder SR, Smith W, Shankar A \& Mitchell P. The long-term relation among retinal arteriolar narrowing, blood pressure, and incident severe hypertension. American Journal of Epidemiology 2008168 80-88. (https://doi.org/10.1093/aje/kwn100)

21 Paisley AN, Izzard AS, Gemmell I, Cruickshank K, Trainer PJ \& Heagerty AM. Small vessel remodeling and impaired endothelialdependent dilatation in subcutaneous resistance arteries from patients with acromegaly. Journal of Clinical Endocrinology and Metabolism 2009 94 1111-1117. (https://doi.org/10.1210/jc.2008-0948)

22 Rizzoni D, Porteri E, Giustina A, De Ciuceis C, Sleiman I, Boari GEM, Castellano M, Muiesan ML, Bonadonna S, Burattin A et al. Acromegalic patients show the presence of hypertrophic remodeling of subcutaneous small resistance arteries. Hypertension $2004 \mathbf{4 3}$ 561-565. (https://doi.org/10.1161/01.HYP.0000114604.52270.05)

23 Maffei P, Dassie F, Wennberg A, Parolin M \& Vettor R. The endothelium in acromegaly. Frontiers in Endocrinology 201910437. (https://doi.org/10.3389/fendo.2019.00437)

24 Chanson P, Bertherat J, Beckers A, Bihan H, Brue T, Caron P, Chabre O, Cogne M, Cortet-Rudelli C, Delemer B et al. French consensus on the management of acromegaly. Annales d'Endocrinologie 200970 92-106. (https://doi.org/10.1016/j. ando.2008.12.011)

25 Chanson P, Arnoux A, Mavromati M, Brailly-Tabard S, Massart C, Young J, Piketty ML, Souberbielle JC \& VARIETE Investigators. Reference values for IGF-I serum concentrations: comparison of six immunoassays. Journal of Clinical Endocrinology and Metabolism 2016 101 3450-3458. (https://doi.org/10.1210/jc.2016-1257)

26 Colao A, Marzullo P \& Lombardi G. Effect of a six-month treatment with lanreotide on cardiovascular risk factors and arterial intimamedia thickness in patients with acromegaly. European Journal of Endocrinology 2002146 303-309. (https://doi.org/10.1530/ eje.0.1460303)
27 Koch E, Rosenbaum D, Brolly A, Sahel JA, Chaumet-Riffaud P, Girerd X, Rossant F \& Paques M. Morphometric analysis of small arteries in the human retina using adaptive optics imaging: relationship with blood pressure and focal vascular changes. Journal of Hypertension 201432 890-898. (https://doi.org/10.1097/ HJH.0000000000000095)

28 Rosenbaum D, Koch E, Girerd X, Rossant F \& Pâques M. Imaging of retinal arteries with adaptative optics, feasibility and reproducibility. Annales de Cardiologie et d'Angeiologie 201362 184-188. (https://doi. org/10.1016/j.ancard.2013.04.017)

29 Gallo A, Mattina A, Rosenbaum D, Koch E, Paques M \& Girerd X. Retinal arteriolar remodeling evaluated with adaptive optics camera: relationship with blood pressure levels. Annales de Cardiologie et d'Angeiologie 201665 203-207. (https://doi.org/10.1016/j. ancard.2016.04.021)

30 Maione L, Brue T, Beckers A, Delemer B, Petrossians P, BorsonChazot F, Chabre O, François P, Bertherat J, Cortet-Rudelli C et al. Changes in the management and comorbidities of acromegaly over three decades: the French Acromegaly Registry. European Journal of Endocrinology 2017176 645-655. (https://doi.org/10.1530/EJE-161064)

31 Tellatin S, Maffei P, Osto E, Dassie F, Famoso G, Montisci R, Martini C, Fallo F, Marra MP, Mioni R et al. Coronary microvascular dysfunction may be related to IGF-1 in acromegalic patients and can be restored by therapy. Atherosclerosis 2018269 100-105. (https:// doi.org/10.1016/j.atherosclerosis.2017.12.019)

32 Bogazzi F, Battolla L, Spinelli C, Rossi G, Gavioli S, Di Bello V, Cosci C, Sardella C, Volterrani D, Talini E et al. Risk factors for development of coronary heart disease in patients with acromegaly: a five-year prospective study. Journal of Clinical Endocrinology and Metabolism 200792 4271-4277. (https://doi.org/10.1210/jc.20071213)

33 Che W, Lerner-Marmarosh N, Huang Q, Osawa M, Ohta S, Yoshizumi M, Glassman M, Lee JD, Yan C, Berk BC et al. Insulin-like growth factor-1 enhances inflammatory responses in endothelial cells: role of Gab1 and MEKK3 in TNF-alpha-induced c-Jun and NF-kappaB activation and adhesion molecule expression. Circulation Research 200290 1222-1230. (https://doi.org/10.1161/01. res.0000021127.83364.7d)

34 Bäck K, Islam R, Johansson GS, Chisalita SI \& Arnqvist HJ. Insulin and IGF1 receptors in human cardiac microvascular endothelial cells: metabolic, mitogenic and anti-inflammatory effects. Journal of Endocrinology 2012215 89-96. (https://doi.org/10.1530/JOE-12-0261)

35 Briet C, Ilie MD, Kuhn E, Maione L, Brailly-Tabard S, Salenave S, Cariou B \& Chanson P. Changes in metabolic parameters and cardiovascular risk factors after therapeutic control of acromegaly vary with the treatment modality. Data from the Bicêtre cohort, and review of the literature. Endocrine 201963 348-360. (https://doi. org/10.1007/s12020-018-1797-8)

36 Kawasaki R, Cheung N, Mosley T, Islam AFM, Sharrett AR, Klein R, Coker LH, Knopman DS, Shibata DK, Catellier D et al. Retinal microvascular signs and 10-year risk of cerebral atrophy. Stroke 2010 41 1826-1828. (https://doi.org/10.1161/STROKEAHA.110.585042)

37 Nägele MP, Barthelmes J, Ludovici V, Cantatore S, von Eckardstein A, Enseleit F, Lüscher TF, Ruschitzka F, Sudano I \& Flammer AJ. Retinal microvascular dysfunction in heart failure. European Heart Journal 201839 47-56. (https://doi.org/10.1093/eurheartj/ehx565)

38 Rosenbaum D, Kachenoura N, Koch E, Paques M, Cluzel P, Redheuil A \& Girerd X. Relationships between retinal arteriole anatomy and aortic geometry and function and peripheral resistance in hypertensives. Hypertension Research 201639 536-542. (https:// doi.org/10.1038/hr.2016.26)

39 Maison P, Démolis P, Young J, Schaison G, Giudicelli JF \& Chanson P. Vascular reactivity in acromegalic patients: preliminary evidence for regional endothelial dysfunction and increased sympathetic 
vasoconstriction. Clinical Endocrinology 200053 445-451. (https:// doi.org/10.1046/j.1365-2265.2000.01127.x)

40 De Ciuceis C, Agabiti Rosei C, Caletti S, Trapletti V, Coschignano MA, Tiberio GAM, Duse S, Docchio F, Pasinetti S, Zambonardi F et al. Comparison between invasive and noninvasive techniques of evaluation of microvascular structural alterations. Journal of Hypertension 201836 1154-1163. (https://doi.org/10.1097/ HJH.0000000000001677)

41 Paques M, Brolly A, Benesty J, Lermé N, Koch E, Rossant F, Bloch I $\&$ Girmens JF. Venous nicking without arteriovenous contact: the role of the arteriolar microenvironment in arteriovenous nickings. JAMA Ophthalmology 2015133 947-950. (https://doi.org/10.1001/ jamaophthalmol.2015.1132)
42 Klein R, Sharrett AR, Klein BE, Chambless LE, Cooper LS, Hubbard LD \& Evans G. Are retinal arteriolar abnormalities related to atherosclerosis? The Atherosclerosis Risk in Communities Study. Arteriosclerosis, Thrombosis, and Vascular Biology 200020 1644-1650. (https://doi.org/10.1161/01.atv.20.6.1644)

43 Raffetto JD, Barros YVR, Wells AK \& Khalil RA. MMP-2 induced vein relaxation via inhibition of [Ca2+]e-dependent mechanisms of venous smooth muscle contraction. Role of RGD peptides. Journal of Surgical Research 2010159 755-764. (https://doi.org/10.1016/j.jss.2008.09.022)

44 Rudling M, Parini P \& Angelin B. Effects of growth hormone on hepatic cholesterol metabolism. Lessons from studies in rats and humans. Growth Hormone and IGF Research 19999 (Supplement A) 1-7. (https://doi.org/10.1016/s1096-6374(99)80002-1)

Received 19 September 2019

Revised version received 30 December 2019

Accepted 23 January 2020 